\title{
Mesenchymal stem cells in prostate cancer have higher expressions of SDF-1, CXCR4 and VEGF
}

\author{
Guanxiong Ding ${ }^{1 *}$, Lujia Wang ${ }^{1 *}, \mathrm{Hua}^{\mathrm{X}}{ }^{1 \star}$, Zheng $\mathrm{Xu}^{3 *}$, Chenchen Feng ${ }^{1}$, Qiang Ding1, \\ Zujun Fang ${ }^{1}$, Zhong $\mathrm{Wu}^{1}$, Haowen Jiang ${ }^{1}$, Jianfeng $\mathrm{Xu}^{1,2}$ and Peng Gao ${ }^{1}$ \\ ${ }^{1}$ Department of Urology, Huashan Hospital, Fudan University, Shanghai, China \\ ${ }^{2}$ Department of Urology, Wake Forest University School of Medicine, Winston-Salem, North Carolina, USA \\ ${ }^{3}$ Department of Urology, Nanjing First Hospital Affiliated to Nanjing Medical University, Nanjing, China
}

\begin{abstract}
Our previous study found that the activity of PCa-MSCs, which could stimulate the cell proliferation of RM-1, was significantly different compared to BMMSCs. Our results indicated that it could be mediated in part by growth factors/chemokines, which were involved in the different activity between two kinds of MSCs (PCa-MSCs and BMMSCs). Normal MSCs (BMMSCs) were isolated from the femur, tibia of the normal mice; prostate tumor MSCs (PCa-MSCs) were obtained from the mice implanted with prostate tumor. Analysis of the expression of SDF-1, CXCR4, VEGF, bFGF and vWF of two kinds of MSCs were examined by ELISA, Realtime-PCR and Western blotting. The expressions of SDF-1 and CXCR4 in PCa-MSCs were higher compared to BMMSCs. Expressions of bFGF and vWF were higher in PCa-MSCs yet the difference did not reach statistical significance. The expression of VEGF was significantly higher in PCa-MSCs. Our data showed that activity of PCa-MSCs was significantly improved compared with BMMSCs, which seemed to have an intrinsic, cell-specific capacity localized to PCa. It could be induced by some factors or chemokines such as SDF-1, CXCR4, and VEGF. The possible role of PCa-MSCs in the process of PCa development needed further clarification.
\end{abstract}

Key words: Prostate cancer - Mesenchymal stem cells - Chemokines

\begin{abstract}
Abbreviations: PCa, prostate cancer; MSCs, mesenchymal stem cells; SDF-1, stromal cell-derived factor-1; CXCR4, CXC chemokine receptor 4; VEGF, vascular endothelial growth factor; bFGF, basic fibroblast growth factor; vWF, von Willebrand factor; BMP-2, bone morphogenetic protein-2; IL-6, 8, 11, interleukin-6, 8, 11; M-CSF, macrophage colony-stimulating factor; MMP-9, metalloproteases-9.
\end{abstract}

\section{Introduction}

Prostate cancer ( $\mathrm{PCa}$ ) is a common malignancy and is the second leading cause of cancer death in males (Jemal et al. 2004). Although early diagnosis of PCa improves clinical outcome, metastatic PCa remains a late-stage event with a poor prognosis. PCa has a striking tendency to metastasize

\footnotetext{
* These authors contributed equally to this work.

Correspondence to: Peng Gao, Department of Urology, Huashan Hospital, Fudan University, 12 Central Wulumuqi Road, Shanghai 200000, China

E-mail: GP_fudan@126.com
}

to bone. Recent work has aimed at identifying key molecules involved in metastasis as therapeutic targets. Therefore, the potential targets for PCa therapy include tumor cell antigens that bind to molecules found at these principal sites of metastasis (Condon 2005).

Mesenchymal stem cells (MSCs) give rise to the different hematopoietic microenvironmental cells including vascular smooth muscle-like stromal cells, adipocytes, osteoblasts, and, more controversially, endothelial cells. MSCs also generate cells that do not belong to the hematopoietic microenvironment. These cells can be mesodermal in origin (Dezawa et al. 2005), but may also be neuroectodermal (Kikuchi et al. 2011) or endodermal cells (Chagraoui et al. 
2003). MSCs can also serve as 'tumor stromal cells', targeting invasive and metastatic malignant tumor cells (Nakamura et al. 2004). Djouad et al also find that MSCs can display side effects related to systemic immunosupression favoring tumor growth in vivo (Garfias et al. 2012). Because the microenvironment of solid tumor $(\mathrm{PCa})$ is similar to the environment of injured/stressed tissue (Ben-Baruch 2003; Khayat 2012), it is logical to hypothesize that PCa may provide a permissive environment for the engraftment of exogenously given MSCs (Zou et al. 2012).

In our previous study, we identified the homing of MSCs to the subcutaneously implanted prostate tumors on mice and we succeeded to isolate the MSCs (PCa-MSCs) from the implanted prostate tumors. We also found that the viability of PCa-MSCs was obviously higher than normal MSCs (BMMSCs). Besides, the activity of PCa-MSCs which could stimulate the cell proliferation by RM-1 was significantly different compared to BMMSCs. Our results indicate that it may be mediated at least in part by growth factors/chemokines (Ding et al. 2012). This study aims at finding out the growth factors or chemokines (SDF-1, CXCR4, VEGF, bFGF and vWF), which can be involved in the different activities between two kinds of MSCs (PCa-MSCs vs. BMMSCs).

\section{Materials and Methods}

\section{Cell lines and animal modes}

RM-1 cells were purchased from the Institute of Cell Biology, Shanghai, China and cultured in DMEM supplemented with $10 \%$ fetal bovine serum, $100 \mathrm{U} / \mathrm{ml}$ penicillin, $100 \mathrm{~g} / \mathrm{ml}$ streptomycin at $37^{\circ} \mathrm{C}$ in a humidified $5 \% \mathrm{CO}_{2}$ incubator. Twelve BALB/c nude mice were inoculated subcutaneously with RM-1 cells were used as the mode of prostate cancer while the control group consists of eight BALB/c nude mice were injected by the physiological saline. The time and the efficiency of the cancer formation were measured.

\section{MSC stem cell isolation and culture}

We used the methods described by Peister et al. (2004). Briefly, MSCs of the normal mice (BMMSCs) form the femur, tibia; humerus taken on axenic conditions was gained by washing of PBS (phosphate buffered solution) and filtrated through the 200 -mesh sieve net. CD105 positive cells selected by the magnetic bead were cultured in DMEM-LG medium containing $10 \%$ fetal bovine serum. Prostate tumors were obtained within 15 days following injection (Ding et al. 2012). Tumor tissue isolated from the prostate cancer mice was cut into the $3 \mathrm{~mm}^{3}$ cube. PCa-MSCs were gained after filtration through the 200-mesh sieve net and centrifugation. Also, CD105 positive cells selected by the magnetic bead were cultured in DMEM-LG medium containing 10\% fetal bovine serum.

\section{Comparison of two kinds of MSCs}

We compared the grow ability of two kinds of MSCs (BMMSCs vs. PCa-MSCs) via the growth curve. The RM-1 cell concentration was adjusted to $1 \times 10^{7} / \mathrm{ml}$ by RPMI1640. The RM-1 cells were grown in 96-well culture plates (Nunc Inc.) with $1 \times 10^{6} /$ well density and each well received 100 ul (about $0.5 \sim 1 \mu \mathrm{Ci}$ ) tritium labeled thymidine $(3 \mathrm{H}-$ TdR). Then they were added with different concentrations $(1: 1,1: 2,1: 3,1: 4$ and 1:5) of BMMSCs or PCa-MSCs, respectively. The 96-well culture plates aforementioned were cultured in DMEM/F12 medium $\left(37^{\circ} \mathrm{C}, 5 \% \mathrm{CO}_{2}\right)$ for $12 \sim$ $16 \mathrm{~h}$. After the end of the culture, the cells were collected on glass fiber filter paper with natural drying. Every minute scintillation counting $(\mathrm{cpm})$ values were determined by beta liquid scintillation counter. The PBS was set as control group in the study.

\section{ELISA}

For determination of SDF-1 levels in conditioned medium, BMMSCs and PCa-MSCs cells were plated to an initial density of $2.0 \times 10^{5}$ cells $/ \mathrm{cm}^{2}$ in Ham's F-12/DMEM $(1: 1, \mathrm{v} / \mathrm{v})$ medium containing $10 \%$ FBS, antibiotics, $10 \mathrm{mM} \beta$-glycerol phosphate, and $10 \mu \mathrm{g} / \mathrm{ml} \mathrm{L}$-ascorbate in 24-well plates (Life Technologies, Inc., Grand Island, NY). Medium was changed on day 3,5, and 7 . After the cells reached confluence, cells were washed twice in PBS, medium was replaced, and conditioned medium was collected and stored at $-80^{\circ} \mathrm{C}$. Medium was analyzed by sandwich ELISA kits (R\&D Systems, Minneapolis, MN) with a detection range of SDF-1, CXCR4, VEGF, bFGF and vWF, respectively.

\section{Realtime-PCR and Western blotting}

The SDF-1 and CXCR4 were first determined by realtimePCR in BMMSCs and PCa-MSCs. The RT-PCR process was performed as described previously (Taichman and Emerson 1994, 1998; Ponomaryov et al. 2000). Sense and antisense primers were prepared to cross intron/exon boundaries: SDF-1, 5'-CGTCAGCCGCATTGCCCGCT and 3'-GGTCTAGCGGAAAGTCCT (380 bp); CXCR4, 5'GGCAGCAGGTAGCAAAGTGA and 3'-TGATGACAAAGAGGAGGTCGG (341 bp); glyceraldehyde-3- phosphate dehydrogenase, 5'-GACAACAGCCTCAAGATCATC AGC and 3'-AAGTCAGAGGAGACCACCTGGTGC; and $\beta$-actin, 5'-TCCTGTGGCATCCATGAAACTACATTCAATTCC, 3'-GTGAAAACGCAGCTCAGTAACAGTCCGCCTAG (347 bp). The samples underwent thermal cycling at $94^{\circ} \mathrm{C}$ for $1 \mathrm{~min}$ and $60^{\circ} \mathrm{C}$ for $1 \mathrm{~min}$ and $72^{\circ} \mathrm{C}$ 
for $1 \mathrm{~min}$ for 35 cycles for SDF-1, followed by a 10-min extension at $72^{\circ} \mathrm{C}$ (Perkin-Elmer, Foster City, CA). PCR for CXCR4 was performed at $94^{\circ} \mathrm{C}, 55^{\circ} \mathrm{C}$, and $72^{\circ} \mathrm{C}$. False positives and DNA contamination were controlled by omitting reverse transcriptase in control reactions. After concentration was determined with Thermo Nanodrop 1000 spectrophotometer, RNAs were converted to mRNA with PrimeScriptTM RT Reagent Kit (TaKaRa) under the condition of $37^{\circ} \mathrm{C}, 15 \mathrm{~min} ; 85^{\circ} \mathrm{C}, 5 \mathrm{~s}$. Forward and reverse primers of SDF- 1 and CXCR4, and internal control GAPDH were synthesized and were applied in real-time PCR procedure with SYBR Green Premix Ex TaqTM (TaKaRa) in 20 $\mu$ l system on ABI 7500n (Applied Biosystem, Forster City, $\mathrm{CA})$. Samples were run at $95^{\circ} \mathrm{C}, 30 \mathrm{~s}$ and were amplified for 40 cycles $\left(95^{\circ} \mathrm{C}, 5 \mathrm{~s} ; 60^{\circ} \mathrm{C}, 34 \mathrm{~s}\right)$. For each sample, the average value of threshold cycle was normalized to GAPDH level with the formula, $2^{-\Delta \Delta \mathrm{Ct}}$. Results were thus presented by expressional fold over control. Cell pellets were harvested in homogenized buffer containing $20 \mathrm{mmol} / 1$ HEPES buffer (5 mmol/l EDTA, $1 \mathrm{mmol} / \mathrm{l}$ phenylmethysulfonyl fluoride, $1 \mathrm{mmol} / \mathrm{l}$ dithiothreitol, $0.1 \mathrm{mmol} / \mathrm{l}$ leupeptin, $75 \mu \mathrm{mol} / \mathrm{l}$ pepstatin $\mathrm{A}, 150 \mathrm{mmol} / \mathrm{l} \mathrm{NaCl}$, and $0.1 \%$ Triton X-100). Cell lysates of same amount were then resolved on $12 \%$ SDSPAGE. After transferred onto nitrocellulose membranes by means of electro-blot, membranes were incubated with primary antibody, mouse monoclonal antibody of SDF-1 and CXCR4 (Santa Cruz Biotechnology, Santa Cruz, CA) at 1:1000 dilution, respectively.

\section{Statistical analysis}

All data were analyzed by the SigmaStat statistical software (Jandel Scientific, San Rafael CA) and S SigmaPlot (SPSS Inc. Chicago, IL). $p<0.05$ was used to define statistically signifi-

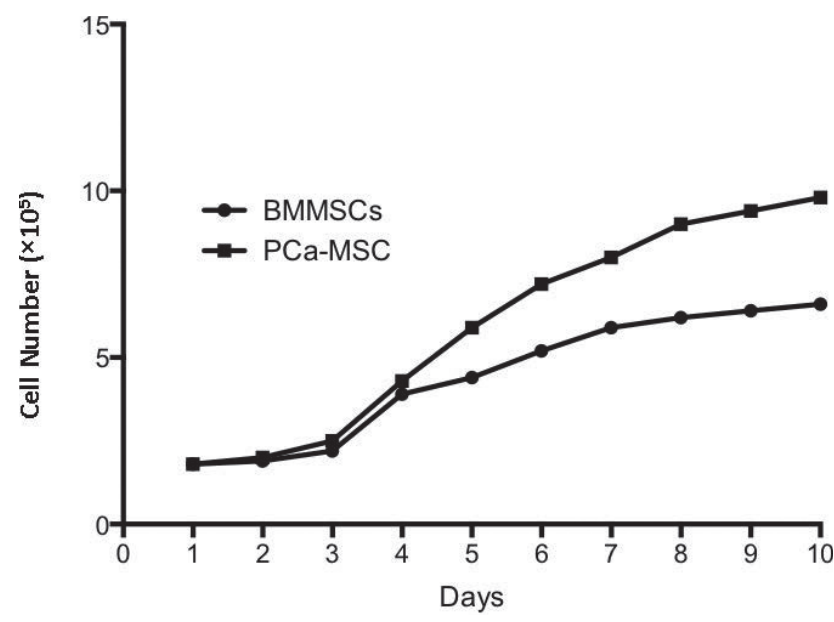

Figure 1. The growth curve of PCa-MSCs and BMMSCs showing a faster growth of PCa-MSCs. cant differences. All experiments were repeated three times with triplicate samples, and similar results were obtained.

\section{Results}

Activity and ability of BMMSCs and PCa-MSCs

In our research, we found that the growth ability of PCaMSCs was obviously higher than BMMSCs. The growth curve of these two kinds of cells was shown in Fig. 1. From the RM1 cell proliferation experiments we found that the activity of PCa-MSCs was also higher than BMMSCs (Fig. 2).

\section{Expressions of SDF-1 and CXCR4}

Expressions of SDF-1 and CXCR4 were investigated with realtime RT-PCR. Expression of SDF-1 and CXCR4 were significantly higher in PCa-MSCs $(p<0.05, n=3$, respectively). Western blotting confirmed the different translation of both factors (Fig. 3).

\section{Expression of SDF-1, CXCR4, VEGF, bFGF and $v W F$}

Recent studies by Taichman et al. (Taichman et al. 2002) have shown that PCa cell lines express functional CXCR4 protein. CXCR4 was additionally shown to be expressed in prostate tissues in vivo. In this study, we first verified the expression of CXCR4 in PCa-MSCs and BMMSCs lines using a commercial mAb against CXCR4, clone 44716. This $\mathrm{mAb}$ was selected because it recognizes multiple CXCR4 conformations, which can be found on many cell lines and types (Baribaud et al. 2001). The results showed that the

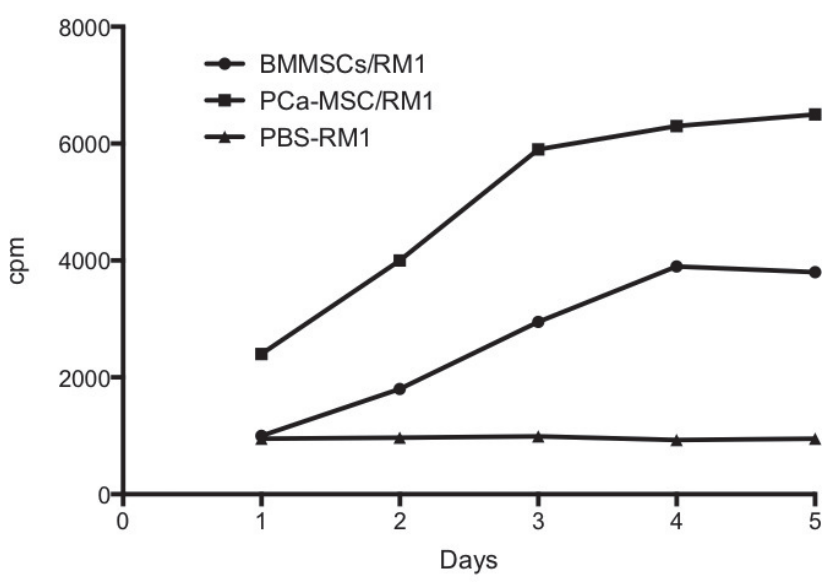

Figure 2. The RM1 cell proliferation experiments evaluated by $3 \mathrm{H}-$ TdR showing the highest proliferation in PCa-MSCs over BMMSCs and control. cpm, count per minute. 


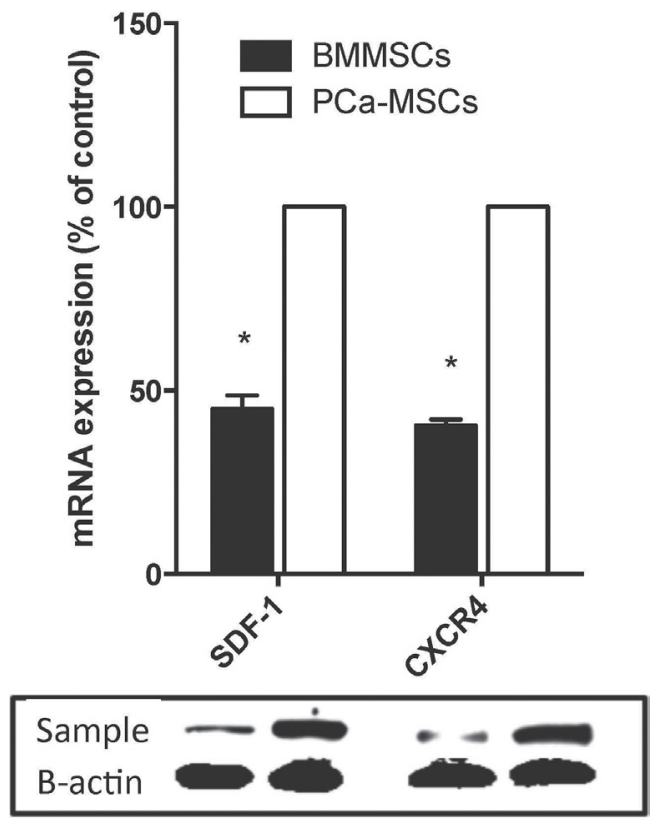

Figure 3. Realtime RT-PCR showing higher expression of SDF-1 and CXCR4 in PCa-MSCs. Expressions were also higher detected by Western blotting $\left(n=3,{ }^{*} p<0.05\right)$.

expressions of SDF-1 and CXCR4 in PCa-MSCs were higher than BMMSCs in the medium. (Fig. 4; $p<0.05$ ). Besides, compared with BMMSCs, levels of VEGF, bFGF and vWF were all higher, but only the expression of VEGF was significantly different in PCa-MSCs (Fig. 5; $p<0.05$ ).

\section{Discussion}

Regardless of their location, all solid tumors will need stroma if they have grown to more than $1 \sim 2 \mathrm{~mm}$ size. Stroma has blood supply to meet the nutrition of the tumor, gas exchange, waste excretion, and the stroma may limit the influx of inflammatory cells, providing a barrier to avoid immune rejection of tumor cells (Dvorak 1986). MSCs in the developmental process contribute to the formation of mesenchymal or connective tissue (including bone, fat, muscle, cartilage and tendons) and usually migrate to the damaged parts of the body to promote wound healing. Similar to wound, tumors can release several growth factors or chemokines such as VEGF to gather the MSCs used to form the stroma (Brower 2005).

MSCs can also secrete VEGF, bFGF, BMP-2, IL-6, IL-8, IL-11 etc., which can promote proliferation of PCa cells. So MSCs may play an important regulatory role in the growth of prostate cancer. Zhang (2010) reports that the surface of MSCs has a variety of cytokine receptors that might have some influence on cell growth, and subsequent experiments have confirmed that some cytokines secreted by PCa cells (PC-3) such as IL-6, M-CSF, bFGF, VEGF and EGF have critical roles in proliferation of MSCs in vitro (Wang et al. 2006).

SDF-1 is a subfamily member of the CXC chemokine, and its cell chemotaxis is regulated by CXCR4, which is the only ligand of CXCR4 known so far. Some studies have shown that the SDF-1/CXCR4 has close relationship with proliferation of tumor cells (Kang et al. 2005). Vaday et al. (2004) and Xing et al. (2008) have found the high expression of CXCR4 mRNA in clinical PCa specimens and a variety of PCa cell lines. Recent studies have confirmed that the SDF-1/CXCR4 system plays an important role in tumor invasion. Xing et al. find that CXCR4 has positive expression in several human prostate cancer cell lines with bone metastasis (Xing et al. 2008). At the same time, they have observed that prostate cancer cells can invade through the single layer of endothelial cells in bone marrow through SDF-1/CXCR4, which can be inhibited by CXCR4 antibody. The in vitro adhesion analysis shows that pre-treatment of SDF-1 in prostate cancer cells shows a dose-dependent manner to increase their adhesion ability with endothelial cell. Therefore bone metastasis of PCa may occur through the SDF-1 pathway. Recent studies have confirmed this approach and have found that SDF-1/ CXCR4 can induce cancer cells to secrete MMP-9, (metalloproteases-9) which is created in the growth conditions for bone metastasis of PCa cells (Chinni et al. 2006). MSCs also express SDF-1/CXCR4, a process that may be related with survival, proliferation and migration of MSCs within the tumor microenvironment through autocrine manner (Askari et al. 2003; Kollet et al. 2003). Our study also finds



Figure 4. The expression of CXCR4 in PCa-MSCs and BMMSCs lines verified by a commercial mAb against CXCR4, clone 44716 . The expressions of SDF-1 and CXCR4 in PCa-MSCs were higher than BMMSCs $\left({ }^{*} p<0.05\right)$. 


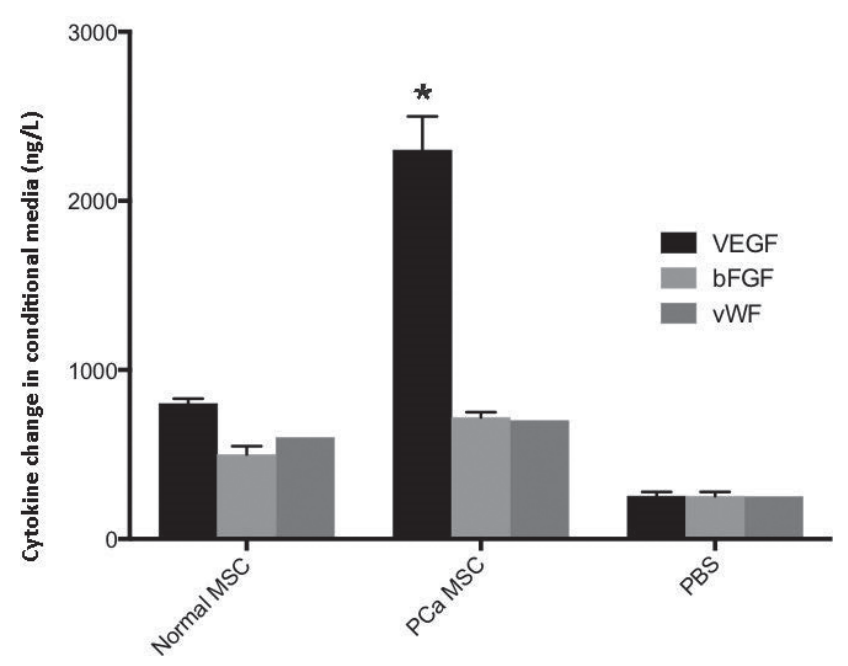

Figure 5. Compared with BMMSCs, levels of VEGF, bFGF and vWF were all higher, but only the expression of VEGF was significantly different in PCa-MSCs $\left({ }^{*} p<0.05\right)$.

the similar results that the SDF-1 and CXCR4 are expressed higher in PCa-MSCs.

It has been reported that MSCs in vivo can differentiate into vascular endothelial cells. Many cytokines play an important role in angiogenesis in vivo. Once the appropriate receptors of MSCs bind with cytokines, it could promote the differentiation of MSCs to mature endothelial cells. VEGF is a specific promoting endothelial cytokinin, which also could stimulate the proliferation of vascular endothelial and angiogenesis (Ferrara 2009). bFGF has a wide range of functional such as cell migration, differentiation and tissue development. It can promote the proliferation, growth and migration of endothelial cells in vitro, which has a strong pro-angiogenic effect in vivo. In addition, bFGF also has the strong role on the proliferation of vascular wall cell, which could promote mitosis of endothelial cell, and enhance their differentiation (Zhang et al. 2007; Li et al. 2009). At the same time it is a powerful capillary proliferation-stimulating agent, to provide adequate blood supply and nutrition for MSCs growth (Yu et al. 2010). Interestingly, we found that the expressions of VEGF in PCa-MSCs were higher than BMMSCs.

Taking these findings together, the PCa-MSCs located in prostate tumor grown in mice have potential higher viability and compared with BMMSCs, which may result from the growth factors or chemokines (SDF-1, CXCR4 and VEGF). Detailed characterization of the properties of MSCs after tumor engraftment should be addressed in future studies.

Acknowledgements. This study was sponsored by a grant from the National Natural Sciences Foundation of China (NSFC) (grant No. 81001145).

\section{References}

Askari A. T., Unzek S., Popovic Z. B., Goldman C. K., Forudi F., Kiedrowski M., Rovner A., Ellis S. G., Thomas J. D., DiCorleto P. E., Topol E. J., Penn M. S. (2003): Effect of stromal-cell-derived factor 1 on stem-cell homing and tissue regeneration in ischaemic cardiomyopathy. Lancet 362, 697-703

http://dx.doi.org/10.1016/S0140-6736(03)14232-8

Baribaud F., Edwards T. G., Sharron M., Brelot A., Heveker N., Price K., Mortari F., Alizon M., Tsang M., Doms R. W. (2001): Antigenically distinct conformations of CXCR4. J. Virol. 75, 8957-8967

http://dx.doi.org/10.1128/JVI.75.19.8957-8967.2001

Ben-Baruch A. (2003): Host microenvironment in breast cancer development: inflammatory cells, cytokines and chemokines in breast cancer progression: reciprocal tumor-microenvironment interactions. Breast Cancer Res. 5, 31-36 http://dx.doi.org/10.1186/bcr554

Brower V. (2005): Search and destroy: recent research exploits adult stem cells attraction to cancer. J Natl Cancer Inst 97, $414-416$ http://dx.doi.org/10.1093/jnci/97.6.414

Chagraoui J., Lepage-Noll A., Anjo A., Uzan G., Charbord P. (2003): Fetal liver stroma consists of cells in epithelial-to-mesenchymal transition. Blood 101, 2973-2982

http://dx.doi.org/10.1182/blood-2002-05-1341

Chinni S. R., Sivalogan S., Dong Z., Filho J. C., Deng X., Bonfil R. D., Cher M. L. (2006): CXCL12/CXCR4 signaling activates Akt-1 and MMP-9 expression in prostate cancer cells: the role of bone microenvironment-associated CXCL12. Prostate 66, 32-48 http://dx.doi.org/10.1002/pros.20318

Condon M. S. (2005): The role of the stromal microenvironment in prostate cancer. Semin. Cancer Biol. 15,132-137 http://dx.doi.org/10.1016/j.semcancer.2004.08.002

Dezawa M., Ishikawa H., Itokazu Y., Yoshihara T., Hoshino M., Takeda S., Ide C., Nabeshima Y. (2005): Bone marrow stromal cells generate muscle cells and repair muscle degeneration. Science 309, 314-317 http://dx.doi.org/10.1126/science.1110364

Ding G. X., Shao J. L., Ding Q., Fang Z. J., Wu Z., Xu J. F., Gao P. (2012): Comparison of the characteristics of mesenchymal stem cells obtained from prostate tumors and from bone marrow cultured in conditioned medium. Exp. Ther. 4, 711-715

Dvorak H. F. (1986): Tumors: wounds that do not heal. Similarities between tumor stroma generation and wound healing. N. Engl. J. Med. 315, 1650-1659 http://dx.doi.org/10.1056/NEJM198612253152606

Ferrara N. (2009): Vascular endothelial growth factor. Arterioscler. Thromb. Vasc. Biol. 29, 789-791 http://dx.doi.org/10.1161/ATVBAHA.108.179663

Garfias Y., Nieves-Hernandez J., Garcia-Mejia M., Estrada-Reyes C., Jimenez-Martinez M. C. (2012): Stem cells isolated from the human stromal limbus possess immunosuppressant properties. Mol. Vis. 18, 2087-2095

Jemal A., Tiwari R. C., Murray T., Ghafoor A., Samuels A., Ward E., Feuer E. J., Thun M. J. (2004): Cancer statistics, 2004. CA Cancer J. Clin. 54, 8-29 http://dx.doi.org/10.3322/canjclin.54.1.8 
Kang H., Mansel R., Jiang W. G. (2005): Benetic manipuladon of stromal cell-derived factor- 1 attests the pivotal role of the autocrine SDF-1-CXCR4 pathway in the aggressiveness of breast cancer cells. Int. J. Oncol. 5, 1429-1434

Khayat D. (2012): Innovative cancer therapies: putting costs into context. Cancer 118, 2367-2371 http://dx.doi.org/10.1002/cncr.26496

Kikuchi M., Hayashi R., Kanakubo S., Ogasawara A., Yamato M., Osumi N., Nishida K. (2011): Neural crest-derived multipotent cells in the adult mouse iris stroma. Genes Cells 16, 273-281 http://dx.doi.org/10.1111/j.1365-2443.2011.01485.x

Kollet O., Shivtiel S., Chen Y. Q., Suriawinata J., Thung S. N., Dabeva M. D., Kahn J., Spiegel A., Dar A., Samira S., Goichberg P., Kalinkovich A., Arenzana-Seisdedos F., Nagler A., Hardan I., Revel M., Shafritz D. A., Lapidot T. (2003): HGF, SDF-1, and MMP-9 are involved in stress-induced human CD34+ stem cell recruitment to the liver. J. Clin. Invest. 112, 160-169

Li C., Zheng Q., Guo X., Quan D., Zhao J. (2009): Combined use of RGD-peptide modified PLGA and TGF-beta1 gene transfected MSCs to improve cell biobehaviors in vitro. J. Huazhong Univ. Sci. Technolog Med. Sci. 29, 592-598 http://dx.doi.org/10.1007/s11596-009-0512-7

Nakamura K., Ito Y., Kawano Y., Kurozumi K., Kobune M., Tsuda H., Bizen A., Honmou O., Niitsu Y., Hamada H. (2004): Antitumor effect of genetically engineered mesenchymal stem cells in a rat glioma model. Gene Ther. 11, 1155-1164 http://dx.doi.org/10.1038/sj.gt.3302276

Peister A., Mellad J., Larson B., Hall B., Gobson L., Prockop D. (2004): Adult stem cells from bone marrow (MSCs) isolated from different strains of in bred mice vary in surface epitopes, rates of proliferation, and differential potential. Blood 103, $1662-1668$ http://dx.doi.org/10.1182/blood-2003-09-3070

Ponomaryov T., Peled A., Peled I., Taichman R. S., Habler L., Sandbank J., Arenzana-Seisdedos G., Nagler A., Lahav M., Szyper-Kravitz M., Zipori D., Lapidot T. (2000): Increased production of SDF- 1 following treatment with DNA damaging agents: relevance for human stem cell homing and repopulation of NOD/SCID mice. J. Clin. Investig. 106, 1331-1339 http://dx.doi.org/10.1172/JCI10329

Taichman R. S., Emerson, S. G. (1994): Human osteoblasts support hematopoiesis through the production of granulocyte colonystimulating factor. J. Exp. Med 179, 1677-1682 http://dx.doi.org/10.1084/jem.179.5.1677
Taichman R. S., Emerson S. G. (1998): The role of osteoblasts in the hematopoietic microenvironment. Stem Cells 16, 7-15 http://dx.doi.org/10.1002/stem.160007

Taichman R. S., Cooper C., Keller E. T., Pienta K. J., Taichman N. S., McCauley L. K. (2002): Use of the stromal cell-derived factor-1/CXCR4 pathway in prostate cancer metastasis to bone. Cancer Res. 62, 1832-1837

Wang J., Levenson A. S., Satcher R. L. Jr. (2006): Identification of a unique set of genes altered during cell-cell contact in an in vitro model of prostate cancer bone metastasis. Int. J. Mol. Med. 17, 849-856

Vaday G. G., Hua S. B., Peehl D. M., Pauling M. H., Lin Y. H., Zhu L., Lawrence D. M., Foda H. D., Zucker S. (2004): CXCR4 and CXCL12 (SDF-1) in prostate cancer: inhibitory effects of human single chain Fv antibodies. Clin. Cancer. Res. 10, 5630-5639 http://dx.doi.org/10.1158/1078-0432.CCR-03-0633

Xing Y., Liu M., Du Y., Qu F., Li Y., Zhang Q., Xiao Y., Zhao J., Zeng F., Xiao C. (2008): Tumor cell-specific blockade of CXCR4/ SDF-1 interactions in prostate cancer cells by hTERT promoter induced CXCR4 knockdown: A possible metastasis preventing and minimizing approach. Cancer Biol. Ther. 7, 1839-1848 http://dx.doi.org/10.4161/cbt.7.11.6862

Yu Y. S., Shen Z. Y., Ye W. X., Huang H. Y., Hua F., Chen Y. H., Chen K., Lao W. J., Tao L. (2010): AKT-modified autologous intracoronary mesenchymal stem cells prevent remodeling and repair in swine infarcted myocardium. Chin. Med. J. 123, 1702-1708

Zhang D. Z., Gai L. Y., Liu H. W., Jin Q. H., Huang J. H., Zhu X. Y. (2007): Transplantation of autologous adipose-derived stem cells ameliorates cardiac function in rabbits with myocardial infarction. Chin. Med. J. 120, 300-307

Zhang X., Li J., Nie J., Jiang K., Zhen Z., Wang J., Shen L. (2010): Differentiation character of adult mesenchymal stem cells and transfection of MSCs with lentiviral vectors. J. Huazhong Univ. Sci. Technolog. Med. Sci. 30, 687-693 http://dx.doi.org/10.1007/s11596-010-0641-Z

Zou W., Zheng H., He T. C., Chang J., Fu Y. X., Fan W. (2012): LIGHT delivery to tumors by mesenchymal stem cells mobilizes an effective antitumor immune response. Cancer Res. 72, 2980-2989

http://dx.doi.org/10.1158/0008-5472.CAN-11-4216

Received: August 7, 2012

Final version accepted: November 21, 2012 